\title{
Research on Clean Heating Technology in Northern Urban China
}

\author{
Yuxing $\mathrm{Li}^{1}$, Yu Shi ${ }^{1}$, Hao $\mathrm{Li}^{1}$, Xuefeng $\mathrm{Gao}^{1}$, Yeyang $\mathrm{Zhu}^{2, *}$ \\ ${ }^{1}$ State Grid Economic And Technical Research Institute Of Jilin Electric Power., LTD \\ ${ }^{2}$ University Of Southern California
}

\begin{abstract}
Currently, with the rapid development of small towns in China, residents' heating demand has been increasing, which exposes the heating problems of the small towns. Especially in the heating season, the energy consumption of buildings accounting for a decent proportion and the increase in pollution emissions can seriously affect the lives of residents. To alleviate these problems and promote clean heating, it is necessary to investigate the resources situation of small towns and design targeted heating lines for load areas. Therefore, this article used data analysis, described the population, construction area and industrial structure of small towns in the northern region, summarized the current development trend of small towns in China. Besides, taking the small towns in Inner Mongolia Autonomous Region as an example, this paper tried to understand the heating problems of small towns, including low energy efficiency of thermal energy and poor thermal insulation of buildings. Based on the supply and demand side of small towns and the differences in the endowment characteristics in various regions, this paper also proposed different clean heating technology paths.
\end{abstract}

\section{Preface}

Small towns are important representatives of urbanization and have different definitions based on different fields. For example, from an administrative perspective, counties and other towns are included in the definition of small towns. Small towns are points of convergence of non-agricultural population. Figure 1 shows the administrative regions of small towns in China. Due to the differences in the economic, social, and industrial structures of small towns, different types of small towns have emerged, such as agricultural towns, industrial towns, and tourist towns. Different from large cities, small towns have abundant resources, including biological resources and wind energy.$^{[1]}$ However, due to development reasons, coal is still the main energy source in many small towns, especially in the north. In winter, heating becomes the largest proportion of building energy consumption.

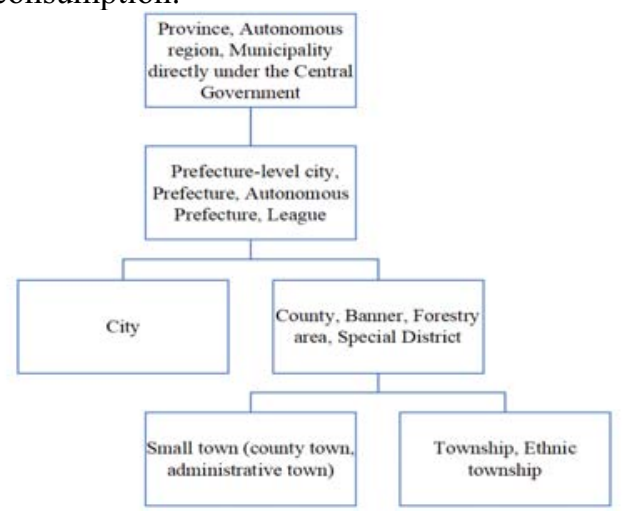

Fig. 1. Administrative Division of Small Towns
According to the 2020 Statistical Bulletin on National Economic and Social Development issued by the National Bureau of Statistics in 2020, the urbanization rate exceeded $60 \%$ by the end of 2020 , and the growth rate has kept stable. The permanent population of urban residents in China has grown rapidly from the original 170 million to 850 million, with a net increase of 680 million. The current urbanization rate is profoundly changing the basis of urban development in China. However, under such a development trend, it is necessary to carefully consider the issue of urban heating. In 2019, China's total annual energy consumption was 4.86 billion tons of standard coal, of which coal consumption was $57.7 \%$. Although coal consumption decreased by $1.5 \%$ compared to last year, fossil energy is still China's main energy source, which is due to the impact of economic costs. In the short term, the cities in the northern region still use fossil energy for heating, and the region accounts for $83 \%$ of the total heating area.

Although China is currently promoting large-scale energy-saving renovations, due to the impact of capital and technology, these renovations are carried out from large cities, and the old buildings in small towns have not been alleviated and improved. Facing severe environmental and energy problems, small towns need to develop clean heating methods that meet the actual needs of life and improve the quality of life of residents through the use of low-consumption clean energy, highefficiency heat supply and other methods. ${ }^{[2]}$ Therefore, this article focuses on the clean heating renovation technology of northern cities and towns. Before the discussion, it is necessary to clarify that the essence of clean heating is to reduce the consumption of fossil

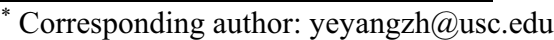


energy and reduce the emission of pollutants under the conditions of meeting thermal comfort. This requires the transformation of multiple procedures of energy supply to reduce the loss of energy supply in the system's transportation, and to eventually achieve the effect of clean heating.

\section{ANALYSIS OF THE CURRENT SITUATION OF HEATING SUPPLY IN SMALL TOWNS}

\subsection{Features of small towns}

\subsubsection{Demographic features}

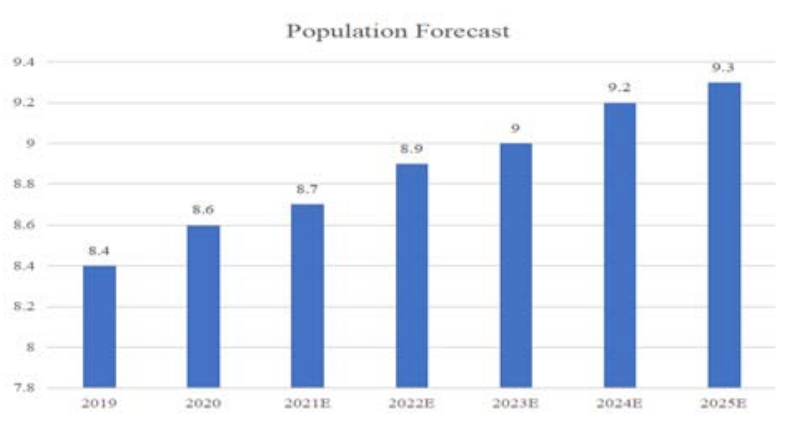

Fig. 2. Urban Population Forecast for 2019-2025

According to the urban population forecast for 20192025, the number of the urban population in China is increasing year by year. According to the spatial distribution map of the permanent population of the county towns, the large towns in the northwest area only exist in towns along the Longhai Railway, and the population of other towns is all less than 50,000. The population of towns in Hebei and Northeast China is in the range of 50,000 to 100,000 . Shandong and Henan provinces are relatively densely populated. The resident population has exceeded 100,000. The uneven distribution of the urban population in the region and geographic differences have led to differences in the urban construction area and heating demand, which increases the difficulty of district heating.

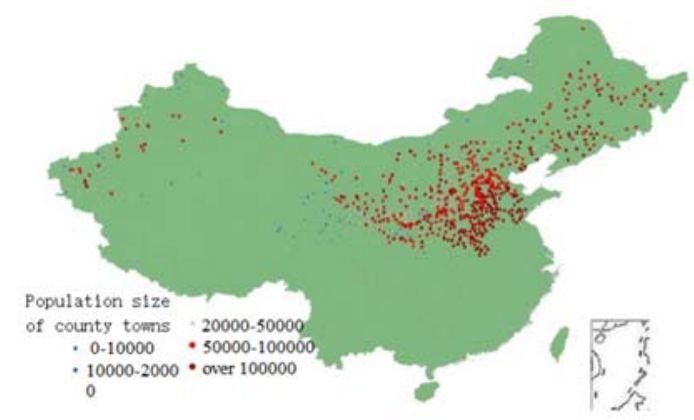

Fig. 3. Geographical distribution of permanent residents in county towns

\subsubsection{Industry features}

According to online data, the current development of urban areas can be understood. Figure 4 shows the distribution of the primary industry in small towns in northern China. The proportion of expenses in the southeast part is higher than that in the northwest part, and non-agricultural activities account for less than 50\% in the northwest part. There might be trade-oriented towns. Meanwhile, there are a large number of agricultural-oriented towns in northeastern China, and these urban areas are very rich in biological resources.

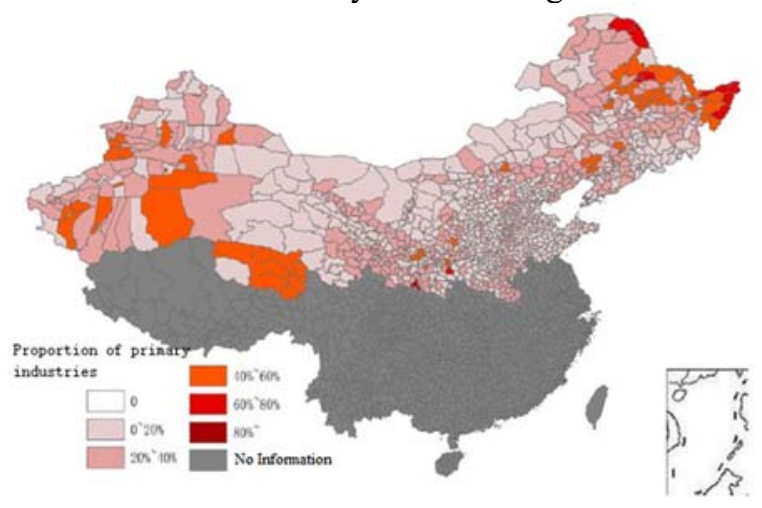

Fig. 4. Proportion of industries in the northern urban region

\subsection{Current situation of heating supply in small towns}

According to published data, China's heating supply is mostly central heating, supplemented by other heating methods. At the end of 2016, the construction area in northern urban and rural areas reached 20.6 billion square meters, of which the construction area in urban areas took $68.4 \%$. The heating method in the area is coal-fired heating, and the heating area can reach $83 \%$. Only a few areas use natural gas, biomass energy and industrial waste for heating. ${ }^{[3-5]}$ During the heating season, the northern area can consume more than 400 million tons of standard coal per year, and urban areas consume $19 \mathrm{~kg}$ standard coal per square meter.

In northern urban areas, central heating is mainly achieved through combined heat and power and largescale centralized boiler houses. The area that can be heated is 7 billion square meters. The uncovered areas use small-scale boilers, with coal, natural gas or renewable energy. Although the area of central heating has been expanded, the heating rates in Shandong and Shaanxi are relatively low, which is related to the local climatic conditions. The central heating rates of Qinghai, Xinjiang, and Gansu are also relatively low due to the low population density. 


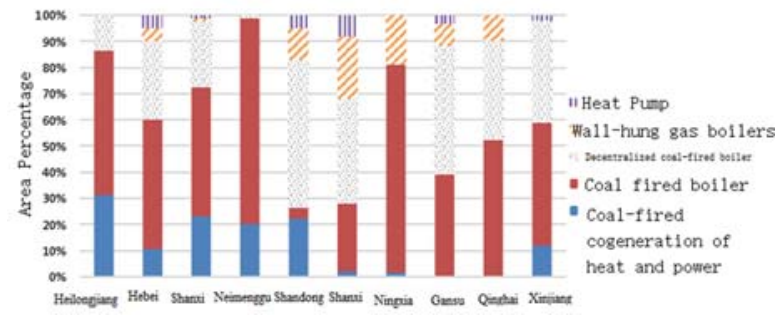

Fig. 5. Heat supply in some northern urban regions

\section{Measurement of heat consumption of buildings in small towns in severe cold areas}

In the previous discussion, energy-saving renovation projects in some areas are carried out from cities. At present, renovation projects in towns are lagging behind cities. This phenomenon occurs mainly because the economic conditions of towns are relatively backward, and residents and the government have relatively weak support for energy-saving renovations. However, to better explore the technical route of the energy-saving renovation of towns, small towns in severe cold areas are particularly selected as examples, and the heat consumption of local buildings is measured to analyze the current heat consumption of buildings in towns.

In the survey, a town in Chifeng City, Inner Mongolia Autonomous Region, is selected to measure the heat consumption of buildings. The heating season in the area is from October 15 to April 15 in the following year, the heating cycle is 183 days, and the outdoor temperature during the heating season is $-4.5^{\circ} \mathrm{C}$. The buildings include energy-saving buildings, non-energy saving buildings, ground-floor shops and single-storeyed houses, totaling 20 buildings.

There are obvious differences in the construction structure of the investigated buildings. For example, the energy-saving buildings use energy-saving concrete structures, their outer walls use polystyrene boards with a thickness of $80 \mathrm{~mm}$, the outer windows use three-layer plastic steel windows, and the roof is covered with polystyrene. For non-energy-saving buildings, they use traditional brick-concrete structure, the outer wall contains more hollow bricks. The square uses ordinary mixed clay fired bricks with larger heat transfer coefficients, and have double-layer steel window and double-layer plastic steel windows for external transmission without much warmth protection treatment.

The heat consumption measurement uses special metering equipment to firstly count the heat at the entrance of the building during the heating season, and then measure the indoor temperature. ${ }^{[6]}$ The measurement structure is shown in the figure. The heat consumption of different types of buildings in towns has obvious differences. Three-step energy-saving buildings have the lowest energy consumption, and their cumulative thermal energy consumption in each square is higher.

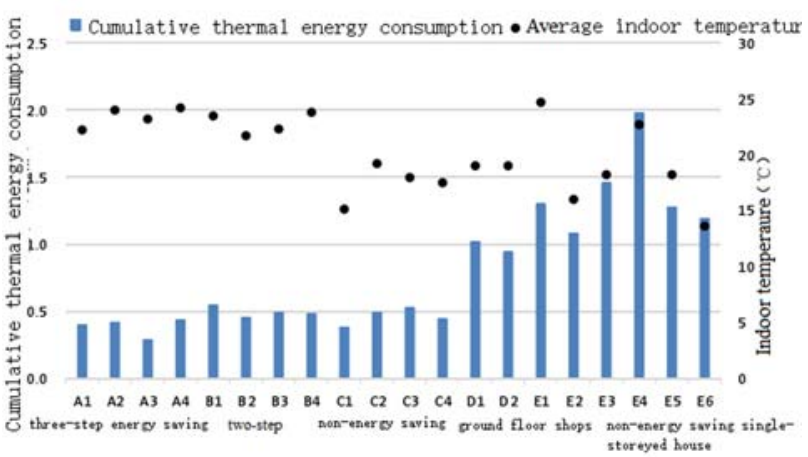

Fig. 6. Thermal energy consumption of different types of buildings in cities and towns

According to the measurement results, due to the increase in the insulation level of the building, the heat load has decreased. It can be found from the energysaving buildings that the ventilation heat loss accounts for the largest proportion. This is because that the building uses the envelope structure to improve its thermal insulation characteristics, but the heat dissipation of other exterior walls, roofs and ground occupies a larger part.

Considering the economic factors of the energysaving renovation of buildings, buildings with relatively poor enveloping structure can be prioritized for renovation. Especially for non-energy saving houses, the renovation can be divided according to the difficulty, such as the investment recovery period for external windows, balconies and doors is relatively short. On the contrary, the investment return period for exterior walls and roofs is very long, which can last for decades. In addition to conventional renovation technology, different energy-saving renovation plans can also be promoted based on local conditions, such as the use of thermal insulation ceilings or curtains. ${ }^{[7]}$ This is because the technical and economic cost of the renovation is relatively small, but the benefits are high. Because the renovation process is relatively simple, it will not affect the normal life of the occupants, which makes the renovation easier.

\section{Research on supply and demand matching and route of clean heating}

Because the main heating method in winter in northern regions is coal-fired boilers, the heating efficiency is low and the emissions are high, which are the core problems that hinder the promotion of clean heating. Meanwhile, small towns are important urban and rural hubs. Compared with large cities, regional clean energy, such as biomass, industrial waste, and wind power, are relatively abundant, but the lack of reasonable planning makes these resources unable to truly show their real effects, so in this article, we use field research to achieve their value.

(1) Heating demand in northern towns

The urban load estimation is the basis for the clean heating plan. According to geographical restrictions, no survey and statistics have been carried out on buildings 
in many northern areas, so the estimation method is used. Based on the actual survey results of small towns in Inner Mongolia and the energy consumption standard, the urban heat load in various regions is determined. In actual investigations, it is found that there are too many non-energy saving buildings and excessive workers in urban residential buildings, and the urban heat value exceeds the standard.

Table 1. Urban building composition and heat consumption estimation

\begin{tabular}{|c|c|c|c|}
\hline Building & $\begin{array}{c}\text { construction } \\
\text { area }\end{array}$ & $\begin{array}{c}\text { Standard heat } \\
\text { consumption } \\
(\mathrm{GJ} / \mathrm{m} 2)\end{array}$ & $\begin{array}{c}\text { Actual heat } \\
\text { consumption } \\
(\mathrm{GJ} / \mathrm{m} 2)\end{array}$ \\
\hline $\begin{array}{c}\text { Three-step } \\
\text { energy- } \\
\text { saving } \\
\text { building }\end{array}$ & $10 \%$ & $\begin{array}{c}\text { reference } \\
\text { value }\end{array}$ & $\begin{array}{c}1.2 \text { times of } \\
\text { reference } \\
\text { value }\end{array}$ \\
\hline $\begin{array}{c}\text { Two-step } \\
\text { energy- } \\
\text { saving } \\
\text { building }\end{array}$ & $25 \%$ & restrictive \\
value \\
$\begin{array}{c}\text { Non energy- } \\
\text { saving } \\
\text { buildings }\end{array}$ & $50 \%$ & $\begin{array}{c}1.2 \text { times of } \\
\text { restrictive } \\
\text { value }\end{array}$ \\
\hline $\begin{array}{c}\text { Single- } \\
\text { storeyed } \\
\text { house }\end{array}$ & $15 \%$ & - & $\begin{array}{c}1.4 \text { times of } \\
\text { the restrictive } \\
\text { value }\end{array}$ \\
\hline
\end{tabular}

Marking the final estimation results, we can know that Shandong and Henan are densely populated, and have rapid urbanization rate, so their heat load is large and concentrated. Because of climate conditions, the northeastern region has a relatively low population density, and dispersed heat load value ranging from 100 MW to $500 \mathrm{MW}$. Relatively speaking, the heat load in the central and western regions is relatively large in the areas close to the railway line, and the rest are kept at $100 \mathrm{MW}$.

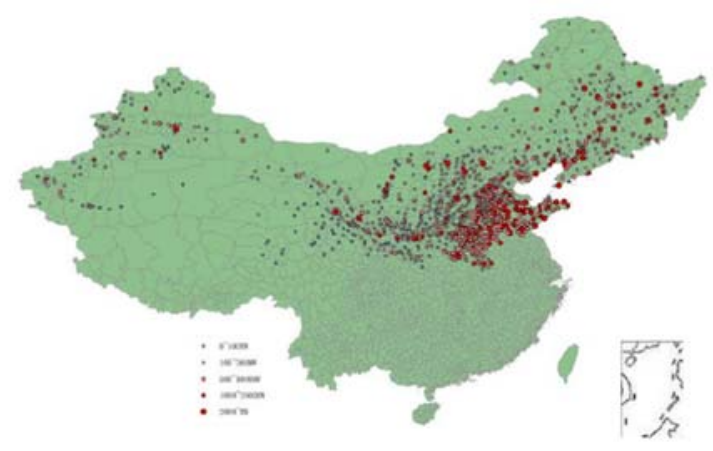

Figure 7. Heat load in northern urban China

(2) Analysis of the current supply and demand for clean heating resources

According to the distribution of regional thermal power plants and regional urban heat load status, the proportion of peak heat load borne by urban thermal power plants can be estimated. According to the diagram, the heating of thermal power plants is highly related to the region. The heating potential of the central region is larger, only part of the northeast regions has thermal power plants with a heating potential of less than $60 \%$. For the western region, heating is very unevenly distributed, and there are no other resources except for the large-capacity thermal power plants along the Longhai Railway.

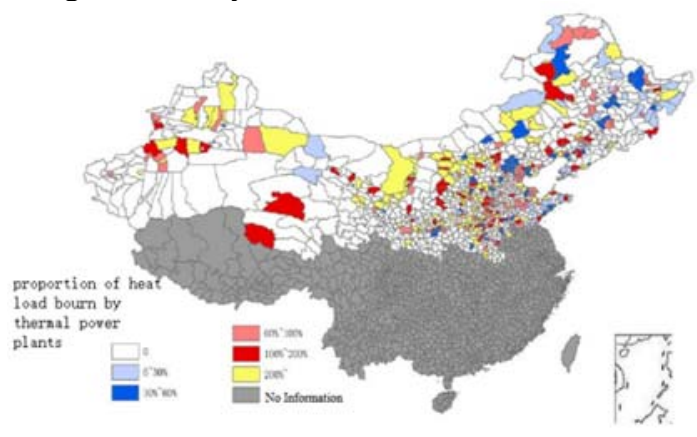

Figure 8. Heat load ratio of thermal power plants in urban areas in the north

Based on the amount of clean energy in various northern provinces, the proportion of heat load is shown in the figure. According to the figure, Jilin, Heilongjiang and Inner Mongolia are relatively rich in biological resources, and Hebei is rich in industrial preheating resources. The thermal power plant has a relatively large proportion of clean energy in each province. ${ }^{[8-9]}$ Except for Beijing, Liaoning and Gansu, the clean energy in all the other provinces exceed the heat load demand. However, we can know from reality that the uneven distribution of resources will make urban clean energy technology routes require more detailed planning.

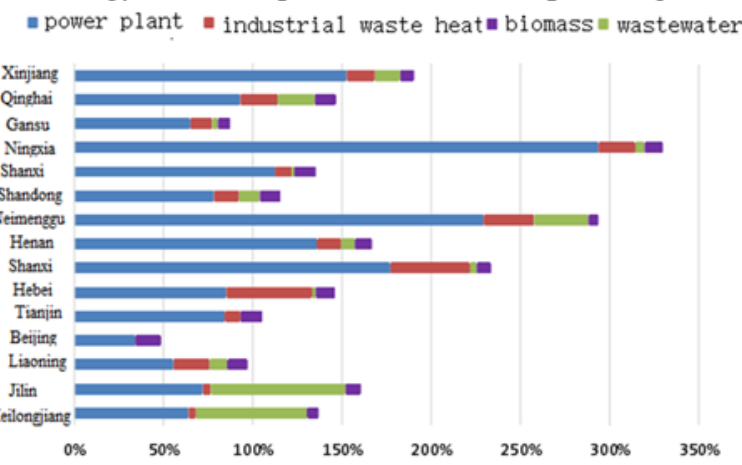

Figure 9. Proportion of clean heating resources in urban heat load in northern provinces

At present, the endowment characteristics of clean heating resources in large cities and small towns in China are quite different. A table drawn from reality shows that currently large cities are dominant and occupy a relatively high proportion. Most cities and towns have clean heating resources. However, small towns are mainly dominated by industrial waste heat and biomass, and clean energy heating resources are absent in small towns. This phenomenon accounts for a relatively large proportion. 
Table 2. Summary of clean heating resources in cities and small towns

\begin{tabular}{|c|c|c|c|c|c|c|c|c|}
\hline \multicolumn{2}{|c|}{ Project } & $\begin{array}{c}\text { Power } \\
\text { plant led }\end{array}$ & $\begin{array}{c}\text { Industry } \\
\text {-led }\end{array}$ & $\begin{array}{c}\text { Biomass } \\
\text { led }\end{array}$ & $\begin{array}{c}\text { Complementary } \\
\text { clean energy }\end{array}$ & $\begin{array}{c}\text { Lack of } \\
\text { clean } \\
\text { energy }\end{array}$ & $\begin{array}{c}\text { No } \\
\text { information }\end{array}$ & Total \\
\hline City & Number & 159 & 15 & 34 & 11 & 70 & 30 & 309 \\
\cline { 2 - 9 } & Area & 48.08 & 4.07 & 3.93 & 5.49 & 35.19 & 2.32 & 99.08 \\
\hline & Number & 130 & 48 & 99 & 9 & 171 & 271 & 728 \\
\cline { 2 - 9 } & Area & 7.11 & 2.40 & 4.31 & 0.51 & 9.43 & 11.05 & 34.82 \\
\hline
\end{tabular}

(3) The design of clean heating route for small towns

By analyzing the different economic routes of heat sources and buildings in small towns in the northern region, heating technology reform measures can be finally put forward. Currently, the heating schemes proposed are as follows:

Reference route: At present, with the development of clean heating in small towns in China, the heat source is maintained as it is. In addition to new buildings and demolition of old buildings, $0.5 \%$ of buildings should be renovated each year, which is related to the slow renovation of buildings. The method is used as the basic plan for comparison with other renovation plans.

Heat source renovation plan: To increase the scale of clean energy usage, but taking into account economic factors, the existing policy in terms of buildings is maintained.

The heat source and rapid renovation route: Based on heat source renovation, increase energy-saving renovation of small towns and upgrade old buildings. This route can be called a "comprehensive renovation route".

Three key milestones can be made in the discussion, the current year, the mid-planning and the long-term planning. However, since there is no clear data comparison and there is no specific numerical determination of the three planning implementation schemes, not much discussion will be done here. However, by the prediction of the clean heating program, if both the energy-saving building renovation and the strict implementation of the national energy-saving standard can be achieved, it is expected to be reduced to $0.317 \mathrm{GI} / \mathrm{m} 2$ in 2035 , compared with the current one of $0.4250 .317 \mathrm{GI} / \mathrm{m} 2$, which has been greatly improved.

\section{Conclusion}

Small towns in the north are developing very rapidly. Combined with the heating needs of residents, it can be found that the backward heat source cannot meet the needs of buildings, and even generates large energy consumption during the heating season in winter, which will aggravate regional pollution and bring serious impacts to residents. Therefore, this article took small towns as research objects and specifically investigated the small towns. The investigation included urban population, building structure and industrial structure, etc., combined with field research data. In-depth discussions on the heating system of small towns in the northern region were conducted, and a clean heating route that met the needs of small towns was designed based on local conditions.

\section{References}

1. Feng Tong, Du Huibin, Coffman D'Maris, Qu Aiyu, Dong Zhanfeng. Clean heating and heating poverty: A perspective based on cost-benefit analysis[J]. Energy Policy,2021,152.

2. Li Jing,Song Lingling,Zhu Yanchun. Subsidies, Clean Heating Choices, and Policy Costs: Evidence from Rural Households in Northern China[J]. Sustainability,2020,13(1).

3. $\mathrm{Hu}$ Zhanping. When energy justice encounters authoritarian environmentalism: The case of clean heating energy transitions in rural China[J]. Energy Research \&amp; Social Science,2020,70.

4. Liang Qiao,Qiao Liang,Liu Doudou,Xu Xiang,Yuan Xueliang. Study on Problems and Countermeasures of Clean Heating in Rural Areas of North China-a Case of Shandong Province[J]. Journal of physics. Conference series,2020,1622(1)

5. Wei TANG,Peng WU,Yu ZHANG. Analysis of Factors Influencing Clean Heating and Research on Sustainable Development Path[A]. Science and Engineering Research Center.Proceedings of 2020 International Conference on Education E-learning and Social Science(EELSS 2020)[C].Science and Engineering Research Center:Science and Engineering Research Center,2020:6.

6. Lin Zhu,Hua Liao,Bingdong Hou,Lin Cheng,Hui Li. The status of household heating in northern China: a field survey in towns and villages[J]. Environmental Science and Pollution Research,2020,27(14).

7. ADB Loan to Pilot Clean Heating Systems, Cut Carbon Emissions in PRC[J]. M2 Presswire,2018.

8. Wen Zheng,Yichi Zhang,Jianjun Xia,Yi Jiang. Cleaner heating in Northern China: potentials and regional balances $[\mathrm{J}]$. Resources, Conservation \&amp; Recycling, 2020,160. 
9. Lili Zhang,Wei Tang,Peng Wu. Study on High Quality Development Path of Clean Heating in North China[A]. Science and Engineering Research Center.Proceedings of 2019 5th International Conference on Education Reform and Modern Management (ERMM 2019) [C].Science and Engineering Research Center:Science and Engineering Research Center, 2019:5. 